\title{
Diagnostic efficacy of computed tomography-guided transthoracic needle aspiration and biopsy in patients with pulmonary disease
}

This article was published in the following Dove Press journal:

OncoTargets and Therapy

4 November 2013

Number of times this article has been viewed

Tibel Tuna'

Sevket Ozkaya ${ }^{2}$

Adem Dirican ${ }^{2}$

Serhat Findik ${ }^{3}$

Atilla G Atici ${ }^{3}$

Levent Erkan ${ }^{3}$

'Department of Pulmonary Medicine, Samsun Chest Diseases and Thoracic Surgery Hospital, ${ }^{2}$ Department of Pulmonary Medicine, Medical Park Samsun Hospital, ${ }^{3}$ Department of Pulmonary Medicine, Faculty of Medicine, Samsun Ondokuzmayis University, Samsun, Turkey
Correspondence: Sevket Ozkaya Medical Park Samsun Hospital, Department of Pulmonary Medicine, Samsun, Turkey Tel +90532474 I309

Email ozkayasevket@yahoo.com
Background: Computed tomography-guided transthoracic needle aspiration (TTNA) and biopsy (TTNB) is a well established, safe, and rapid method of reaching a definitive diagnosis for most thoracic lesions. The present study aimed to determine the roles of TTNA and TTNB in the diagnosis of pulmonary diseases and to compare the results using these two techniques.

Methods: TTNB and TTNA were performed in 105 patients admitted to our clinic due to peripheral pulmonary lesions between May 2005 and November 2007. Needle biopsies were performed using 18-gauge Tru-Cut ${ }^{\mathbb{R}}$ biopsy needles and aspirations was performed using 18-2022-gauge Chiba needles.

Results: Malignant lesions diagnosed by TTNB were non-small cell lung carcinoma (51 patients, $73 \%$ ), small cell lung carcinoma (nine patients, 13\%), malignant tissue (three patients, 5\%), lymphoma (two patients, 3\%), thymoma (two patients, 3\%), plasmacytoma (one patient, 1\%), rhabdomyosarcoma (one patient, 1\%), and metastasis (one patient, 1\%). The malignant lesions diagnosed by TTNA were non-small cell lung carcinoma in eleven patients (92\%) and malignant tissue in one patient ( $8 \%)$. Three $(100 \%)$ of the benign lesions diagnosed by TTNB were granulomas and two (100\%) benign lesions diagnosed by TTNA were infarctions. When the diagnostic value of TTNB and TTNA was compared, TTNB was significantly superior. Malignant lesions were identified in $70(84 \%)$ and benign lesions were identified in three $(4 \%)$ of the 83 patients in the TTNB group. Ten (12\%) patients in the TTNB group could not be diagnosed. Malignant lesions were found in $12(55 \%)$ and benign lesions were found in two (9\%) of the 22 patients in the TTNA group. Negative results were obtained in eight (36\%) patients. The diagnostic sensitivity, specificity, and accuracy of TTNB was calculated to be $92 \%, 100 \%$, and 93\%, respectively (Table 5). The diagnostic sensitivity, specificity, and accuracy of TTNA was $78 \%, 100 \%$, and $82 \%$, respectively. TTNB had a sensitivity of $92 \%(70 / 76)$ in malignant cases and $100 \%(3 / 3)$ in benign cases, while the sensitivity of TTNA in malignant and benign cases was $75 \%(3 / 4)$ and $67 \%(2 / 3)$, respectively.

Conclusion: TTNB is a safe and easy procedure which provides a highly accurate diagnosis of benign and malignant lung lesions without causing a significant increase in complication rates.

Keywords: computed tomography, guided, transthoracic needle aspiration, transthoracic needle aspiration biopsy, pulmonary lesion

\section{Introduction}

Computed tomography-guided transthoracic needle aspiration (TTNA) and biopsy (TTNB) are well established, safe, and rapid methods for achieving a definitive diagnosis for most thoracic lesions, whether the lesion is located in the pleura, lung parenchyma, or mediastinum. This study aimed to determine the roles of TTNA and 
TTNB in the diagnosis of pulmonary diseases and to compare the results using these two modalities.

\section{Materials and methods}

TTNB and TTNA were performed in 105 patients admitted to our clinic due to peripheral pulmonary lesions between May 2005 and November 2007. The two groups of patients were followed up prospectively. Laboratory blood tests, including platelet count, prothrombin time, and international normalized ratio, were done before the procedure. Lesion localization was defined by computed tomography. No premedication was administered to the patients before the procedure. Needle biopsies were performed using 18-gauge Tru-Cut ${ }^{\circledR}$ (Cook Endoscopy, Winston-Salem, NC, USA) biopsy needles and aspirations were performed using 18-20-22-gauge Chiba needles (Cook Medical Inc., Bloomington, IN, USA). Biopsy and aspiration materials were fixed in alcohol and sent for pathologic examination. All patients were evaluated by computed tomography immediately after the procedure, and those patients at risk for pneumothorax were further evaluated by chest X-ray several hours later. TTNB or TTNA was performed on each patient. Demographic characteristics, history, physical examination findings, laboratory values, radiologic findings, diagnoses, and complication rates were recorded for both groups. Statistical analyses of the data were performed using Statistical Package for the Social Sciences version 13 software (SPSS Inc., Chicago, IL, USA). The results are presented as the mean \pm standard deviation or as percentages. Chi-square analysis and specificity and sensitivity tests were performed for analysis of the data.

\section{Results}

One hundred and five patients, consisting of 19 females and 86 males, were included in the study (Table 1). Their

Table I Clinical and demographic characteristics of the patients

\begin{tabular}{llll}
\hline & TTNB & TTNA & Total \\
\hline Age & $60 \pm 12$ & $59 \pm 8$ & \\
Gender (M/F) & $67 / 16$ & $19 / 3$ & $86 / 19$ \\
Symptoms & & & \\
$\quad$ Chest pain & 27 & 7 & 34 \\
$\quad$ Dyspnea & 20 & 2 & 22 \\
Cough & 18 & 6 & 24 \\
Hemoptysis & 5 & 2 & 7 \\
Fatigue & 9 & 5 & 14 \\
$\quad$ Neck mass & 2 & 0 & 2 \\
$\quad$ No symptoms & 2 & 0 & 2 \\
Total & $83(79 \%)$ & $22(21 \%)$ & 105 \\
\hline
\end{tabular}

Abbreviations: TTNB, transthoracic needle biopsy; TTNA, transthoracic needle aspiration.
Table 2 Radiologic characteristics

\begin{tabular}{lllll}
\hline CT characteristic & TTNB & TTNA & Total & $P$ \\
\hline Mass, n (\%) & $67(86)$ & II (14) & $78(100)$ & $0.006^{*}$ \\
Consolidation, n (\%) & $7(58)$ & $5(42)$ & $12(100)$ & 0.774 \\
Cavity, n (\%) & $4(40)$ & $6(60)$ & $10(100)$ & 0.754 \\
Nodule, n (\%) & $5(100)$ & $0(0)$ & $5(100)$ & 0.063 \\
Total, n (\%) & $83(79)$ & $22(21)$ & $105(100)$ & $0.00 I^{*}$ \\
\hline
\end{tabular}

Note: $* P<0.05$

Abbreviations: CT, computed tomography; TTNB, transthoracic needle biopsy; TTNA, transthoracic needle aspiration.

mean age was 59.79 (range 20-80) years. The radiologic characteristics in each groups were observed as masses, consolidation, cavities, and nodules on computed tomography (Table 2). The most frequent radiologic lesion was a mass (78 patients, 74\%). Significantly more TTNBs were performed in patients presenting with a mass. No significant difference existed between the two procedures performed in patients with other lesions. Mass lesions were diagnosed as malignant and benign in $97 \%$ and $3 \%$ of patients, respectively (Table 3).

Lesion localizations on computed tomography were as follows: 35 (33.3\%) in the right upper lobe; $14(13.3 \%)$ in the right middle lobe; $16(15.2 \%)$ in the right lower lobe; $16(15.2 \%)$ in the left upper lobe; eight $(7.6 \%)$ in the lingula; and $16(15.2 \%)$ in the left lower lobe.

A definitive diagnosis was established in 87 of the 105 patients evaluated using a transthoracic procedure. The lesion was malignant in $82(78 \%)$ patients and benign in five $(5 \%)$ patients. Eighteen (17\%) of the patients could not be diagnosed (Table 4 and Figure 1); of these 18 patients, a diagnosis was later established in ten patients by bronchoscopy $(n=9)$ or clinically $(n=1)$. A definitive diagnosis could not be established in the remaining eight patients (four in the TTNB group and four in the TTNA group).

The malignant lesions diagnosed by TTNB were nonsmall cell lung carcinoma in $51(73 \%)$ patients, small cell lung carcinoma in nine $(13 \%)$ patients, malignant tissue in three $(5 \%)$ patients, lymphoma in two $(3 \%)$ patients, thymoma in two $(3 \%)$ patients, plasmacytoma in one $(1 \%)$

Table 3 Distribution of malignant and benign lesions according to CT characteristics

\begin{tabular}{llll}
\hline CT characteristic & Malignant & Benign & Total \\
\hline Mass, n (\%) & $66(97)$ & $2(3)$ & $68(100)$ \\
Consolidation, n (\%) & $7(88)$ & I (I2) & $8(100)$ \\
Cavity, n (\%) & $6(86)$ & I (14) & $7(100)$ \\
Nodule, n (\%) & $3(75)$ & $1(25)$ & $4(100)$ \\
Total, n (\%) & $82(94)$ & $5(6)$ & $87(100)$ \\
\hline
\end{tabular}

Abbreviation: CT, computed tomography. 
Table 4 Rates of diagnosis with TTNB and TTNA

\begin{tabular}{lllll}
\hline Diagnosis & TTNB & TTNA & Total & $\boldsymbol{P}$ \\
\hline Positive, $\mathrm{n}(\%)$ & $73(84)$ & $14(16)$ & $87(100)$ & $0.02 \mathrm{I}$ \\
Negative, $\mathrm{n}(\%)$ & $10(56)$ & $8(44)$ & $18(100)$ & \\
Total, $\mathrm{n}(\%)$ & $83(79)$ & $22(2 \mathrm{I})$ & $105(100)$ & \\
\hline
\end{tabular}

Abbreviations: TTNB, transthoracic needle biopsy; TTNA, transthoracic needle aspiration.

patient, rhabdomyosarcoma in one patient (1\%), and metastasis in one (1\%) patient (Figure 2 and Figure 3).

The malignant lesions diagnosed by TTNA were non-small cell lung carcinoma in $11(92 \%)$ patients and malignant tissue in one $(8 \%)$ patient. Three $(100 \%)$ of the benign lesions diagnosed by TTNB were granulomas, and two (100\%) benign lesions diagnosed by TTNA were infarctions (Figure 2). When the diagnostic values of TTNB and TTNA were compared, TTNB was significantly superior ( $P=0.021$, Table 4 ).

Malignant lesions were identified in $70(84 \%)$ and benign lesions were identified in three (4\%) of the 83 patients in the TTNB group. Ten (12\%) patients in the TTNB group could not be diagnosed (Figure 1). Malignant lesions were found in $12(55 \%)$ and benign lesions were found in two (9\%) of the 22 patients in the TTNA group. Negative results were obtained in eight (36\%) patients (Figure 1).

The diagnostic sensitivity, specificity, and accuracy for TTNB was calculated to be $92 \%, 100 \%$, and $93 \%$, respectively (Table 5). The diagnostic sensitivity, specificity, and accuracy for TTNA was $78 \%, 100 \%$, and $82 \%$, respectively (Table 6). TTNB had a sensitivity of $92 \%(70 / 76)$ in malignant cases and $100 \%(3 / 3)$ in benign cases, while the sensitivity of TTNA in malignant and benign cases was $75 \%$ (3/4) and $67 \%(2 / 3)$, respectively.

The most frequent complication during the transthoracic procedures was pneumothorax (eleven patients, 10\%). There was no statistically significant difference in complication rates

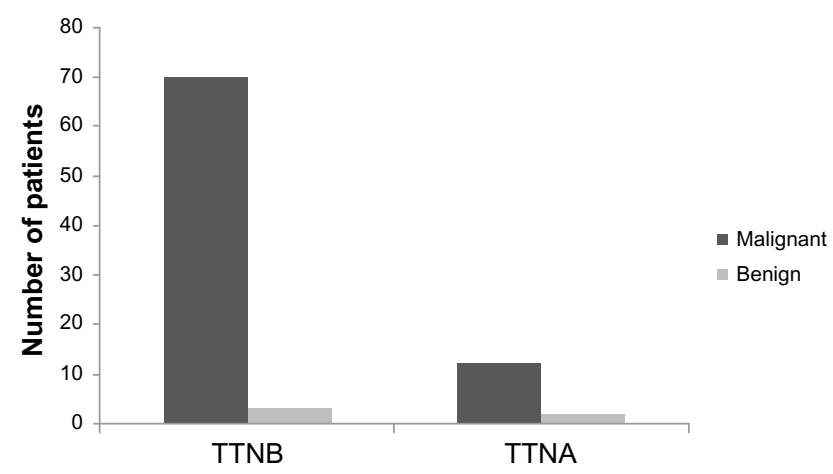

Figure I Distribution of malignant and benign lesions diagnosed by TTNB and TTNA. Abbreviations: TTNB, transthoracic needle biopsy; TTNA, transthoracic needle aspiration.

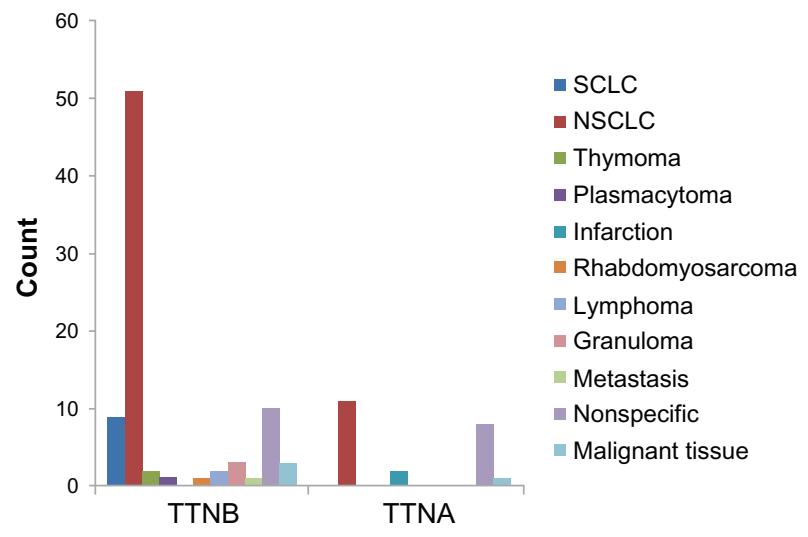

Figure 2 Pulmonary lesions diagnosed by TTNB and TTNA.

Abbreviations: TTNB, transthoracic needle biopsy; TTNA, transthoracic needle aspiration; NSCLC, non-small cell lung cancer; SCLC, small cell lung cancer.

between the two procedures (Table 7). Chest tubes were placed in four of seven patients who developed pneumothorax during TTNB; three patients were monitored conservatively. A pneumothorax occurred in four patients during TTNA. Chest tubes were placed in two of the four patients, whereas the other two patients improved after monitoring and oxygen therapy.

\section{Discussion}

TTNA is a successful method that is performed in the diagnosis of malignant disease and the presence of a pathologist during the procedure increases the diagnostic value. ${ }^{1}$ However, it is difficult to provide this arrangement in many centers. The sensitivity has been reported to be lower in benign lesions, ranging between $11 \%$ and $88 \%{ }^{2,3}$ In agreement with previous studies, the sensitivity of TTNA in malignant and benign lesions in the present study was $75 \%$ and $67 \%$, respectively. When sampling pulmonary lesions, there is considerable interinstitutional variability in the technical performance of percutaneous needle biopsy of the lung, some performing computed tomography-guided fine needle aspiration biopsy for cytologic evaluation, others choosing percutaneous core biopsy of the lung, and others using a combination of both. ${ }^{4}$ Typically, percutaneous core biopsy of the lung involves insertion of a hollow large-bore needle, with a specially adapted cutting mechanism, into an organ to extract a

Table 5 Diagnostic values in patients in whom transthoracic needle biopsy (TTNB) was performed

\begin{tabular}{lll}
\hline & Number & Percentage (\%) \\
\hline Sensitivity & $73 / 79$ & 92 \\
Specificity & $4 / 4$ & 100 \\
Positive predictive value & $73 / 73$ & 100 \\
Negative predictive value & $4 / 10$ & 40 \\
Accuracy & $77 / 80$ & 93 \\
\hline
\end{tabular}


Table 6 Diagnostic values in patients in whom transthoracic needle aspiration (TTNA) was performed

\begin{tabular}{lll}
\hline & Number & Percentage (\%) \\
\hline Sensitivity & $14 / 18$ & 78 \\
Specificity & $4 / 4$ & 100 \\
Positive predictive value & $14 / 14$ & 100 \\
Negative predictive value & $4 / 8$ & 50 \\
Accuracy & $18 / 22$ & 82 \\
\hline
\end{tabular}

piece of tissue for histologic evaluation. ${ }^{5}$ While technically demanding, extensive experience documents percutaneous core biopsy of the lung as a safe and accurate procedure with limited morbidity and rare mortality. ${ }^{4-7}$ When compared with fine needle aspiration biopsy, percutaneous core biopsy of the lung seems to achieve a superior diagnostic accuracy for benign lung lesions (71\%-97\%) and a similarly high diagnostic accuracy for malignant lung tumors ( $88 \%-95 \%)$ with a comparable complication risk and without the need for onsite cytopathology. ${ }^{8-12}$

Kallenberg et al reported that transthoracic needle biopsy is a safe diagnostic procedure in patients with hematologic malignancies and has the potential of making specific diagnoses with minimal morbidity. In 53 patients with hematologic malignancies who underwent transthoracic needle biopsy during 1999-2007, the most common underlying hematologic malignancy was non-Hodgkin's lymphoma $(n=20)$. Lesions were most frequently located in the left upper lobe $(n=16) ; 33$ lesions were pleural-based and nine had cavitation. Transthoracic needle biopsy established specific diagnoses in 22 patients (malignancies in 12 and infections in ten). Sensitivity for malignancy was $50.0 \%$, sensitivity for infection was $40.0 \%$, and there were no falsepositive results. ${ }^{13}$

A study of 15,865 adults who had transthoracic needle biopsy of a pulmonary nodule found a $15 \%$ risk of pneumothorax, with $6.6 \%$ of all biopsies requiring a chest tube. Patients aged 60-69 years, smokers, and those with chronic obstructive pulmonary disease had higher risk for complications. ${ }^{14}$

Table 7 Complications during TTNB and TTNA

\begin{tabular}{lllll}
\hline Complications & TTNB & TTNA & Total & $P$ \\
\hline Pneumothorax & 7 & 4 & $\mathrm{II}$ & 0.114 \\
Hemorrhage & $\mathrm{I}$ & 0 & $\mathrm{I}$ & \\
Hemoptysis & 0 & $\mathrm{I}$ & $\mathrm{I}$ & \\
None & 75 & 17 & 92 & \\
Total & 83 & 22 & 105 & \\
\hline
\end{tabular}

Abbreviations: TTNB, transthoracic needle biopsy; TTNA, transthoracic needle aspiration.

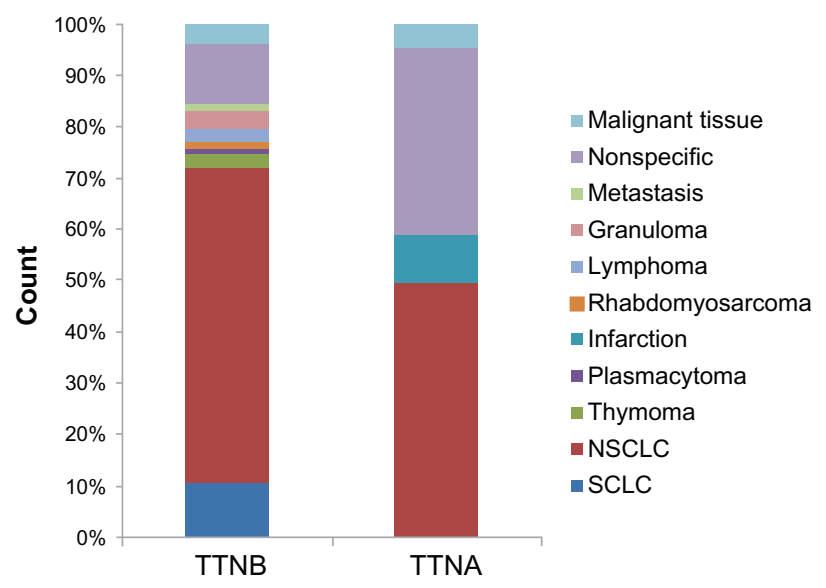

Figure 3 Pulmonary lesions diagnosed by TTNB and TTNA.

Abbreviations: TTNB, transthoracic needle biopsy; TTNA, transthoracic needle aspiration; NSCLC, non-small cell lung cancer; SCLC, small cell lung cancer.

While obtaining more tissue is an advantage using TTNB, higher complication rates are a disadvantage. The sensitivities of TTNB were 92\% (70/76) and 100\% $(3 / 3)$ in malignant and benign cases, respectively. Thus, TTNB was shown to be superior to aspiration in both conditions. On the other hand, there was no statistically significant difference in complication rates between the two procedures.

In conclusion, TTNB is a safe and easy procedure which provides a highly accurate diagnosis of benign and malignant lung lesions without causing a significant increase in complication rates.

\section{Disclosure}

The authors report no conflicts of interest in this work.

\section{References}

1. Santambrogio L, Nosotti M, Bellaviti N, Pavoni G, Radice F, Caputo V. CT-guided fine-needle aspiration cytology of solitary pulmonary nodules: a prospective, randomized study of immediate cytologic evaluation. Chest. 1997;112:423-425.

2. Lillington GA, Gould MK. Identification of benign pulmonary nodules by needle biopsy. Chest. 1998;113:3-5.

3. Khouri NF, Stitik FP, Erozan YS, et al. Transthoracic needle aspiration biopsy of benign and malignant lung lesions. AJR Am J Roentgenol. 1985; 144:281-288.

4. Richardson CM, Pointon KS, Manhire AR, et al. Percutaneous lung biopsies: a survey of UK practice based on 5444 biopsies. Br J Radiol. 2002;75:731-735.

5. Gupta S, Wallace MJ, Cardella JF, Kundu S, Miller DL, Rose SC; Society of Interventional Radiology Standards of Practice Committee. Quality improvement guidelines for percutaneous needle biopsy. J Vasc Interv Radiol. 2010;21:969-975.

6. Manhire A, Carig M, Clelland C, et al. Guidelines for radiologically guided lung biopsy. Thorax. 2003;58:920-936.

7. Berquist TH, Bailey PB, Cortese DA, Miller WE. Transthoracic needle biopsy: accuracy and complications in relation to location and type of lesion. Mayo Clin Proc. 1980;55:475-481. 
8. Moulton JS, Moore PT. Coaxial percutaneous technique with automated biopsy devices: value in improving accuracy and negative predictive value. Radiology. 1993;186:515-522.

9. Stanley JH, Fish GD, Andriole JG, et al. Lung lesions: cytologic diagnosis by fine needle biopsy. Radiology. 1987;162:389-391.

10. Lucidarme O, Howarth N, Finet JF, Grenier PA. Intrapulmonary lesions: percutaneous automated biopsy with a detachable, 18-gauge, coaxial cutting needle. Radiology. 1998;207:759-765.

11. Laurent F, Latrabe V, Vergier B, Michel P. Percutaneous CT-guided biopsy of the lung: comparison between aspiration and automated cutting needle using a coaxial technique. Cardiovasc Intervent Radiol. 2000;23:266-272.
12. Yeow KM, See LC, Lui KW, et al. Risk factors for pneumothorax and bleeding after CT-guided percutaneous coaxial cutting needle biopsy of lung lesions. J Vasc Interv Radiol. 2001;12:1305-1312.

13. Kallenberg MH, Gill RR, Factor RE, et al. Diagnostic efficacy and safety of computed tomography-guided transthoracic needle biopsy in patients with hematologic malignancies. Acad Radiol. 2009;16: 1408-1415.

14. Wiener RS, Schwartz LM, Woloshin S, Welch HG. Population-based risk for complications after transthoracic needle lung biopsy of a pulmonary nodule: an analysis of discharge records. Ann Intern Med. 2011;155:137-144.

\section{Publish your work in this journal}

OncoTargets and Therapy is an international, peer-reviewed, open access journal focusing on the pathological basis of all cancers, potential targets for therapy and treatment protocols employed to improve the management of cancer patients. The journal also focuses on the impact of management programs and new therapeutic agents and protocols on

\section{Dovepress}

patient perspectives such as quality of life, adherence and satisfaction The manuscript management system is completely online and includes a very quick and fair peer-review system, which is all easy to use. Visit http://www.dovepress.com/testimonials.php to read real quotes from published authors.

Submit your manuscript here: http://www.dovepress.com/oncotargets-and-therapy-journal 